\title{
The Time Profile of the Cost Structure in Pakistan's Manufacturing Sector
}

\author{
EATZAZ AHMAD and MUHAMMAD IDREES
}

\section{INTRODUCTION}

The manufacturing sector of Pakistan has at times played the role of the leading sector of the economy. The successful experience of planned growth in the 1960s owes much to the special attention paid to the growth of manufacturing sector. Policies like the export bonus scheme, tax-holidays, subsidised import of capital, easy and subsidised loans and over-valued exchange rate, resulted in a substantial growth in the sector. However, with over-protection of the sector, nationalisation of some of the major industries in the 1970s and, later-on, over-employment in the nationalised industries, the performance of the sector started to deteriorate gradually. It is now widely believed that many of the manufacturing industries in Pakistan have become inefficient because they have not been exposed to competitive environment due to protective and distortionary policies.

It is to be expected that distortions like those mentioned would have not only eroded the performance but also affected the behaviour of the manufacturing sector. It is therefore important to determine how productivity growth in the manufacturing sector has been retarded over time and what type of changes in technology have taken place in terms of their effects on factor intensities and on the firms, reaction to such changes in factor prices. An analysis of the changes over time in production technology of the manufacturing sector may provide an answer to these questions.

The present study aims at analysing changes in the cost structure of Pakistan's manufacturing sector over the past two decades in order to study the nature and speed of productivity growth; determine whether there exists any factor bias in the technological changes; and to analyse how technology has adjusted to absorb changes in the relative factor prices. We prefer to study to cost structure rather than

Eatzaz Ahmad and Muhammad Idrees are Professor and Ph.D. student, respectively, in the Department of Economics, Quaid-i-Azam University, Islamabad. 
the production function since an estimated cost function, along with the related input demand functions, provides statistically more efficient information on all the essential properties of technology.

The nature of productivity growth can be analysed by studying the time path of the estimated cost function holding factor prices and output level constant. Likewise factor bias in technological changes can be inferred from the time paths of factor shares in the cost of production. Finally, to analyse the nature of adjustment in technology in response to changes in the relative factor prices, we shall trace the time paths of substitution elasticities between factor inputs.

A number of earlier studies have analysed productivity, factor intensities and substitution between factor inputs in the manufacturing sector of Pakistan. Most of these studies are based on CES (constant elasticity of substitution) production function or its variants [e.g. Battese and Malik (1987, 1988); Battese et al. (1993); Kazi et al. (1976); Kazmi (1981); Kemal (1981); Khan (1989); Khan and Rafiq (1993) and Zahid et al. (1992)]. A few studies have based their analysis on a flexible functional form, namely the Translog cost function [see Burki et al. (1997); Mahmood (1989, 1992); Chishti and Mahmud $(1988,1991)]$. The present postulates Generalised Leontief cost function, which is also flexible and has recently been found to perform better than the Translog cost function in Idrees (1998).

The paper is planned as follows. Section 2 presents the framework of analysis. Data and construction of variables are discussed in Section 3. Section 4 presents the results, while Section 5 concludes the study.

\section{ANALYTICAL FRAMEWORK}

\section{Specification of Technology}

We have decided to base our analysis on the Generalised Leontief cost function for two main reasons. First, there is recent evidence to suggest that the Generalised Leontief cost function has a better performance than the Translog function [see Idrees (1998)]. Second, like the Translog function, the Generalised Leontief cost function is quite flexible and is linear in parameters like the Translog function. There is no strong reason to stick to the same function that has been estimated in a number of earlier studies. The Generalised Leontief cost function and the associated input demand functions are given by [see Guilkey et al. (1983)]:

$$
\begin{aligned}
& C=\sum_{i=1}^{n} \sum_{j=1}^{n} \alpha_{i j}\left(P_{i} P_{j}\right)^{1 / 2} Q+\sum_{i=1}^{n} \alpha_{i} P_{i} Q^{2}+\sum_{i=1}^{n} \beta_{i} P_{i}, \quad \alpha_{i j}=\alpha_{j i} \quad \ldots \\
& X_{i}=\sum_{j=1}^{n} \alpha_{i j}\left(P_{j} / P_{i}\right)^{1 / 2} Q+\alpha_{i} Q^{2}+\beta_{i} \quad \ldots \quad \ldots \quad \ldots \quad \ldots \quad \ldots
\end{aligned}
$$


As can be seen, the cost function is quadratic in output level for the given input prices and quadratic in the square roots of input prices for the given output level. The system satisfies homogeneity (in factor prices) and adding-up properties without any restrictions on parameters. The Cost function is non-homothetic unless very rigid restrictions are imposed on the cost function. Finally, notice that all the parameters of the cost function appear in the input demand functions as well and, hence, the input demand functions provide complete information on cost structure.

\section{Changes in Cost Structure over Time}

The above formulation can be further generalised to introduce changes in the cost structure over time. These changes can take place due to various reasons such as technological change, factor market distortions and the varying degree of utilisation of the factors of production, especially capital and labour. In Pakistan underutilisation of labour is an important issue in the public sector. Employment in the public sector has been generated not solely on the basis of economic factors, but also on moral and political grounds. For the sake of convenience, we shall also refer to the changes in the cost structure as a technical change.

Following the neo-classical formulation, we introduce disembodied and exogenous technical change by making parameters of the cost function dependent on time, denoted $t$. That is,

$$
\begin{array}{ccccccc}
\alpha_{i j}=a_{i j}^{0}+a_{i j}^{1} t & \ldots & \ldots & \ldots & \ldots & \ldots & \ldots \\
\alpha_{i}=a_{i}^{0}+a_{i}^{1} t & \ldots & \ldots & \ldots & \ldots & \ldots & \ldots \\
\beta_{i}=b_{i}^{0}+b_{i}^{1} t & \ldots & \ldots & \ldots & \ldots & \ldots & \ldots
\end{array}
$$

In these equations the intercept shows the value of the corresponding parameter at time zero, while the slope indicates its rate of change per unit of time. The above formulation allows for a variety of technical changes from where it is possible to determine the direction and speed of technical change, the presence of factor bias and the changing pattern of substitution elasticities.

Substituting the above equations in the cost and input demand functions (1) and (2), we have

$$
\begin{aligned}
C & =\sum_{i=1}^{n} \sum_{j=1}^{n} a_{i j}^{0}\left(P_{i} P_{j}\right)^{1 / 2} Q+\sum_{i=1}^{n} a_{i}^{0} P_{i} Q^{2}+\sum_{i=1}^{n} b_{i}^{0} P_{i} \\
& +\sum_{i=1}^{n} \sum_{j=1}^{n} a_{i j}^{1}\left(P_{i} P_{j}\right)^{1 / 2} Q t+\sum_{i=1}^{n} a_{i}^{1} P_{i} Q^{2} t+\sum_{i=1}^{n} b_{i}^{1} P_{i} t, \quad a_{i j}^{0}=a_{j i}^{0}, a_{i j}^{1}=a_{j i}^{1} \ldots
\end{aligned}
$$




$$
X_{i}=\sum_{j=1}^{n} a_{i j}^{0}\left(P_{j} / P_{i}\right)^{1 / 2} Q+a_{i}^{0} Q^{2}+b_{i}^{0}+\sum_{j=1}^{n} a_{i j}^{1}\left(P_{j} / P_{i}\right)^{1 / 2} Q t+a_{i}^{1} Q^{2} t+b_{i}^{1} t \ldots(7)
$$

We now consider the effect of changing parameters on cost efficiency and factor intensity. If we study the historical pattern of the estimated unit cost of production, it will include the effects of built-in economies or diseconomies of scale (e.g. due to variable returns to scale), changing relative factor prices and technology changes. To untangle the technological factor from the estimated unit cost, we must control for the effects of scale and the relative factor prices on the unit cost. Thus assuming that output and factor prices are held constant, say at $P_{i}^{*}$ and $Q^{*}$ respectively, we can treat them as constants and write the unit cost, the optimal input quantities and factor cost shares as functions of time as follows.

$$
\begin{array}{lllll}
c(t)=\frac{C(t)}{Q^{*}}=\sum_{k=1}^{n} P_{k}^{*} A_{k}+\sum_{k=1}^{n} P_{k}^{*} B_{k} t & \ldots & \ldots & \ldots & \ldots \\
X_{i}(t)=A_{i}+B_{i} t & \ldots & \ldots & \ldots & \ldots \\
S_{i}(t)=\frac{P_{i}^{*} A_{i}+P_{i}^{*} B_{i} t}{\sum_{k=1}^{n} P_{k}^{*} A_{k}+\sum_{k=1}^{n} P_{k}^{*} B_{k} t} & \ldots & \ldots & \ldots & \ldots
\end{array}
$$

For the study of changes in total factor productivity over time, consider the time derivative of (8):

$$
\frac{\partial c(t) / \partial t}{c(t)}=\frac{\sum_{k=1}^{n} P_{k}^{*} B_{k}}{\sum_{k=1}^{n} P_{k}^{*} A_{k}+\sum_{k=1}^{n} P_{k}^{*} B_{k} t} \quad \ldots \quad \ldots \quad \ldots \quad \ldots
$$

If this time derivative is negative (positive) the total factor productivity, holding prices and output constant, will be increasing (decreasing) over time.

To explore the existence of factor bias with respect to the changing cost structure, we use Hicks classification of technical change. Thus the changes in cost structure are referred to as factor ' $\mathrm{i}$ ' saving/using if and only if the cost share of factor ' $i$ ' decreases/increases over time. If the cost share of factor ' $i$ ' remains constant then the changes in cost structure are classified as neutral with respect to factor ' $i$ ' [see Jones (1975), pp. 163-167]. The rate of change in the factor shares evaluated at fixed output and factor prices can be determined from Equation (10) as follows. 


$$
\frac{\partial S_{i}(t)}{\partial t}=\frac{P_{i} B_{i} \sum_{k=1}^{n} P_{k}^{*} A_{k}-P_{i} A_{i} \sum_{k=1}^{n} P_{k}^{*} B_{k}}{\left[\sum_{k=1}^{n} P_{k}^{*} A_{k}+\sum_{k=1}^{n} P_{k}^{*} B_{k} t\right]^{2}} \quad \ldots \quad \ldots \quad \ldots \quad \ldots
$$

\section{Changing Patterns of Substitution Elasticities}

The elasticity of substitution between two factor inputs can be defined as the elasticity of the input ratio with respect to marginal rate of substitution. For the case of more than two inputs this elasticity would depend on the assumptions about the prices and quantities of the other inputs. We shall use Allen partial elasticity of substitution, which assumes that the prices of the other inputs are held constant. This elasticity is given by [see McFadden (1978)]:

$$
\begin{array}{lllllll}
\sigma_{i j}=\frac{C C_{i j}}{C_{i} C_{j}} & \ldots & \ldots & \ldots & \ldots & \ldots & \ldots
\end{array}
$$

where $C$ is total cost, $C_{i}=\partial \mathrm{C} / \partial P_{i}=X_{i}$, and $C_{i j}=\partial^{2} C / \partial P_{i} \partial P_{j}=\partial X_{i} / \partial P_{j}=\partial X_{j} / \partial P_{i}$.

In case of Generalised Leontief cost function the Allen partial elasticity of substitution is given by [see Guilkey et al. (1983)]:

$$
\sigma_{i j}=\left[0.5\left(\alpha_{i j}^{0}+\alpha_{i j}^{1} T\right) Q P_{i}^{-1 / 2} P_{j}^{-1 / 2}\right]\left[C / X_{i} X_{j}\right] \ldots \quad \ldots \quad \ldots
$$

Finally, the direct or Hicks elasticity of factor demand $\varepsilon_{i j}=\partial \log X_{i} / \partial \log P_{j}$ can be obtained from Allen partial elasticity as follows [see Mahmood (1989)]:

$$
\begin{array}{llllllll}
\varepsilon_{i j}=\sigma_{i j} S_{j} & \ldots & \ldots & \ldots & \ldots & \ldots & \ldots & \ldots
\end{array}
$$

Since the parameters appearing in Allen and Hicks elasticities are time dependent, these elasticities can also be evaluated for each period while holding the prices and output constant.

\section{THE DATA}

Our main data source is the Census of Manufacturing Industries (CMI) which has been published irregularly for the years 1969-70, 1970-71, 1975-76 to 1987-88 and 1990-91. Since the sample of sixteen years is not large enough, we have pooled provincial level data for Punjab and Sindh. These two provinces account for more than 80 percent of the manufacturing firms. This procedure has been supported in Battese and Malik (1987) and Malik et al. (1989). 
The CMI provides information on the value of production at current prices. To obtain real output, the value of production for each year is deflated by the wholesale price index for manufacturing sector, the latter taken from the Monthly Statistical Bulletin. The wage rate is calculated by dividing the employment cost with average daily persons engaged. The data on employment cost and average daily persons engaged are given in CMI.

Measurement of the capital cost and price is a difficult job as admitted by many researchers [e.g. Christensen and Jorgenson (1969, 1970)]. The most appropriate price of capital for our purpose is the user cost of capital, which is calculated as follows.

$$
P_{K}=P_{M}\left(r+\delta-\pi_{M}\right) \quad \ldots \quad \ldots \quad \ldots \quad \ldots \quad \ldots
$$

where $P_{K}$ is the user cost of capital, $P_{M}$ is price index of capital goods (machinery), $r$ is the rate of interest, $\delta$ is the capital depreciation rate and $\pi_{M}$ is the rate of growth in the price index of capital. The data on price index of machinery are taken from Monthly Statistical Bulletin and are used as a proxy for price index of capital both for Punjab and Sindh. The rate of interest is calculated by taking the average scheduled banks' rate on long term advances to manufacturing sector. This information is also available from the Monthly Statistical Bulletin. The depreciation rate is calculated by dividing the total depreciation with the value of fixed assets at the beginning of the year. The total depreciation and the value of fixed assets at the beginning of the year are available in the CMI. The quantity of capital is obtained by dividing the value of capital by the price index of machinery and the total user cost of capital is worked out by multiplying the quantity of capital by the user cost.

Energy input includes four major categories: electricity, natural gas, petroleum products (furnace oil, kerosene oil, petrol, diesels of various varieties, etc.) and coke and coal (coke, coal, charcoal, firewood, etc.). Information on the quantity of all the energy inputs used is available from the CMI. Data are also available on the cost of inputs except for the electricity produced and consumed by the firms. We assume that the unit cost of generated electricity is the same as that of purchased electricity.

Aggregating the costs of all the energy inputs gives the cost of the aggregate energy input. Using information on the costs and quantities of inputs we have also generated the price series for all the energy inputs. The price and quantity series are then used to construct the Fisher price index of the composite energy input. To derive a quantity index of energy input, we have divided the energy cost by the price index. Finally, the total cost is obtained by adding the costs of labour, capital and energy.

The time variable $t$ is assigned the values $0,1,6$ to 18 and 21 respectively for the years $1969-70,1970-71,1975-76$ to $1987-88$ and $1990-91$ for which the CMI data are available. 


\section{THE RESULTS}

\section{Estimates of the Cost Function}

Since all the parameters in the cost function also appear in the input demand functions, we have estimated only the input demand functions. Due to the presence of across equation parametric restrictions, we have applied Zellner's efficient method of estimation for seemingly unrelated equations. For the linear regression models, as in our case, this method is asymptotically equivalent to the Maximum Likelihood method.

The estimates of Generalised Leontief Model are reported in Table 1. These results show that out of 24 parameters in the system 12 are statistically significant at 5 percent or 10 percent level. Of the significant parameters, 7 are related to the time variable. This means that significant changes in the cost structure have taken place during the period of analysis.

Table 1

Parameters of Generalised Leontief Cost Function

\begin{tabular}{crrrrr}
\hline Parameters & Estimates & $t$-Statistic & Parameters & Estimates & $t$-Statistic \\
\hline$b_{E}^{0}$ & 0.3181 & 5.991 & $b_{E}^{1}$ & 0.0170 & 4.807 \\
$b_{K}^{0}$ & 0.3658 & 0.540 & $b_{K}^{1}$ & -0.1247 & -2.993 \\
$b_{L}^{0}$ & 0.1130 & 1.824 & $b_{L}^{1}$ & -0.0055 & -1.319 \\
$a_{E}^{0}$ & 0.5265 & 7.136 & $a_{E}^{1}$ & -0.0161 & -5.180 \\
$a_{K}^{0}$ & -0.4550 & -0.378 & $a_{K}^{1}$ & -0.0373 & -0.888 \\
$a_{L}^{0}$ & -0.1206 & -1.201 & $a_{L}^{1}$ & 0.0042 & 1.054 \\
$a_{E E}^{0}$ & -0.5769 & -5.486 & $a_{E E}^{1}$ & -0.0241 & -4.669 \\
$a_{K K}^{0}$ & 0.4812 & 0.236 & $a_{K K}^{1}$ & 0.1634 & 2.480 \\
$a_{L L}^{0}$ & 0.0985 & 0.403 & $a_{L L}^{1}$ & -0.0090 & -0.830 \\
$a_{E K}^{0}$ & -0.3212 & -3.443 & $a_{E K}^{1}$ & 0.0312 & 4.940 \\
$a_{E L}^{0}$ & -0.0860 & -1.122 & $a_{E L}^{1}$ & 0.0117 & 2.231 \\
$a_{K L}^{0}$ & 0.0980 & 0.941 & $a_{K L}^{1}$ & 0.0025 & 0.303 \\
\hline
\end{tabular}

The time independent component of the intercept term is positive in each of the input demand equation. The signs of the other parameters are mixed and do not directly signify any particular pattern. The parameters associated with the time variable show the rates of change over time in the coefficients of the input demand 
function. The results show that the intercept term in the energy demand equation has been increasing while the one for capital demand functions has been decreasing over time. Further more both these effects are statistically significant. The intercept term for labour demand has been decreasing though the annual rate of decrease is small and statistically insignificant. Thus the uniform shifts in the input demand functions have been positive in case of energy and negative in case of capital. This means that the changes in the cost structure have resulted in an increased intensity of energy input relative to capital and this factor bias is independent of output level as well as the input price ratios.

The results also show that the cross effects of the prices of energy and capital on each other's demand have significantly increased over time. This means that the demands for energy and capital inputs have become more sensitive to each other's price over time.

A straightforward analysis of the own price and output effects is not possible since these effects are dependent on a large number of parameters. Therefore for further implications of changes in the cost structure, we now study the effect of time on the cost of production and the input cost shares.

\section{Changes in the Cost Structure over Time}

To study the effect of technology on the unit cost of production, we have computed the annual percentage change in unit cost assuming that the output and prices are constant at their respective mean levels in the sample (see Equation 11). The result shows that if the factor prices and output are held constant, the unit cost of production would be increasing at an average rate of 0.04 percent per year. This number is very close to zero. Thus during our period of analysis no major improvement in total factor productivity seems to have taken place.

While rising productivity can be attributed to technological advancement, it would be extra-ordinary to identify any decline in productivity as an outcome of technological deterioration. The decline in productivity as revealed by our estimate can be attributed to a number of possible factors. It is likely that the increasing cost has resulted from a shift in the composition of the manufacturing sector in the direction of relatively inefficient industries due to market distortions. This allocative inefficiency could have resulted from a distorted tariff structure that was meant to protect some industries that were otherwise inefficient. Another possible explanation is that the rate of capacity utilisation has declined over time due to subsidised availability of capital. Another major reason for declining productivity could be overemployment of labour in the public sector, which controls a significant portion of the manufacturing sector. ${ }^{1}$

${ }^{1}$ For example, according to Census of Manufacturing Industries 1990-91, the share of public sector in the ownership of fixed assets in the manufacturing sector was about one-third in 1990-91. 
The results on factor intensities (Equation 12) show that the share of energy in the total cost of production has been increasing at an annual rate of 0.017 percentage points per year while the share of capital has been decreasing by 0.018 percentage points per year. The share of labour has almost been constant (increasing at the rate of 0.0006 percentage points). This result is consistent with our earlier conclusion that a uniform upward shift in energy demand relative to the demand for capital has taken place over time. These results mean that over time capital equipment and machines have gradually been replaced by new varieties that are relatively cheaper and/or more productive but use more energy per unit cost of production.

Thus major changes in the manufacturing sector of Pakistan have taken place that have resulted in an increased intensity of energy consumption, especially at the expense of capital. A plausible explanation for this factor bias is that over the years the traditional production techniques, which by nature used to be more labour intensive, have been replaced gradually by modern techniques that use more energy per unit of output. The results show pronounced increase in energy-capital compared to energy-labour as over-employment of labour in government owned manufacturing sector neutralises the labour-saving effect of modern technology.

In Pakistan most of the investment in plants and equipment is based on imported capital. With rising cost of labour in the developed countries, the new plants are designed to be more efficient and are meant to replace labour by energy. When the same plants are installed in Pakistan, the cost share of energy rises but with over-employed cheap labour in public owned manufacturing units, the cost share of labour is not reduced. And this while the energy intensity could also be increasing due to shift in the composition of manufacturing sector towards more energy intensive industries.

\section{Elasticities of Substitution}

To study the changing pattern of substitution elasticities due to technological change we have calculated all the Allen and Hicks elasticities of substitution for each of the years from 1975-76 to 1990-91 at the mean values of output and factor prices, but allowing variations due to changing parameters. In other words, all the variations in the estimated elasticities are estimated to account solely for the changing cost structure rather than in input prices or output level.

The results on the Allen partial and Hicks elasticities are presented in Table 2. These results show that labour and capital are good substitutes of each other and the magnitude of elasticity is declining slowly but gradually with the passage of time. In 1975-76 the coefficient of Allen's elasticity was 0.738 and it contracted to 0.579 in 1990-91. It appears, however, that the elasticity has relatively stabilised as the annual rate of change in its value has been shrinking over time. 
Table 2

The Time Paths of Allen Partial and Hicks Elasticities of Substitution

\begin{tabular}{lccccccccc}
\hline Year & $\sigma_{K L}$ & $\varepsilon_{K L}$ & $\varepsilon_{L K}$ & $\sigma_{E L}$ & $\varepsilon_{E L}$ & $\varepsilon_{L E}$ & $\sigma_{E K}$ & $\varepsilon_{E K}$ & $\varepsilon_{K E}$ \\
\hline $1975-76$ & 0.738 & 0.194 & 0.541 & -2.023 & -0.531 & -0.087 & -7.258 & -4.23 & -0.23 \\
$1976-77$ & 0.723 & 0.172 & 0.526 & -0.627 & -0.149 & -0.022 & -4.487 & -3.261 & -0.154 \\
$1977-78$ & 0.709 & 0.156 & 0.513 & 0.673 & 0.148 & 0.038 & -1.693 & -1.224 & -0.095 \\
$1978-79$ & 0.695 & 0.143 & 0.500 & 1.252 & 0.258 & 0.092 & -0.658 & -0.474 & -0.048 \\
$1979-80$ & 0.682 & 0.133 & 0.489 & 1.619 & 0.316 & 0.142 & -0.117 & -0.084 & -0.010 \\
$1980-81$ & 0.669 & 0.124 & 0.479 & 1.891 & 0.351 & 0.187 & 0.216 & 0.154 & 0.021 \\
$1981-82$ & 0.658 & 0.116 & 0.470 & 2.109 & 0.374 & 0.229 & 0.442 & 0.316 & 0.048 \\
$1982-83$ & 0.647 & 0.110 & 0.461 & 2.293 & 0.391 & 0.268 & 0.607 & 0.432 & 0.071 \\
$1983-84$ & 0.636 & 0.105 & 0.453 & 2.452 & 0.404 & 0.304 & 0.731 & 0.520 & 0.091 \\
$1984-85$ & 0.627 & 0.100 & 0.445 & 2.594 & 0.414 & 0.338 & 0.829 & 0.589 & 0.108 \\
$1985-86$ & 0.618 & 0.096 & 0.438 & 2.721 & 0.422 & 0.369 & 0.908 & 0.644 & 0.123 \\
$1986-87$ & 0.609 & 0.092 & 0.432 & 2.836 & 0.429 & 0.398 & 0.973 & 0.689 & 0.137 \\
$1987-88$ & 0.601 & 0.088 & 0.427 & 2.942 & 0.435 & 0.426 & 1.028 & 0.727 & 0.149 \\
$1990-91$ & 0.579 & 0.080 & 0.409 & 3.213 & 0.447 & 0.499 & 1.149 & 0.811 & 0.178 \\
\hline Average & 0.668 & 0.123 & 0.463 & 1.920 & 0.354 & 0.298 & 0.249 & 0.178 & 0.030 \\
\hline
\end{tabular}

Note: $\sigma_{i j}$ is the Allen partial elasticity of substitution between inputs $\mathrm{i}$ and $\mathrm{j}$, while $\varepsilon_{i j}$ is the Hicks elasticity of substitution for input $\mathrm{i}$ with respect to the price of input $\mathrm{j}$. The subscripts $\mathrm{K}, \mathrm{L}$ and $\mathrm{E}$ denote the inputs capital, labour and energy respectively.

The same pattern holds for the Hicks elasticities of demand for capital and labour with respect to each other's price. The Hicks elasticities are smaller than the Allen elasticity as could be expected from the relationship between the two types of elasticities (see Equation 16). Furthermore the elasticity of capital with respect to wage rate is smaller than the elasticity of labour with respect to the rental rate of capital. This is so because with a larger cost share of capital than labour, the percentage change in labour demand resulting from a given percentage increase in rental rate would be larger than the effect of an equal percentage increase in wage rate on the demand for capital.

Labour and energy appeared to be close complements of each other until 1975-76. The degree of complementarity, as measured by Allen partial elasticity, declined to one-third in the next year. In 1977-78 the relationship reversed and the two inputs turned into substitutes. Since then the elasticity of substitution between the two pairs has been increasing continuously, though at diminishing rates. Finally in 1990-91 the elasticity of substitution jumped to 3.21. The time paths of the Hick elasticities between labour and energy follow a similar pattern. Their relative magnitudes can be explained on the same lines as the elasticities between labour and capital. 
Finally, Allen partial and Hicks elasticities between capital and energy exhibit almost the same trend as the elasticities between labour and energy. Capital and energy are found to be complements of each other till 1979-80. Later on a substitutability relation emerges between the two inputs. The tendency here again is that the degree of substitutability has been rising over time at a declining rate.

The above results show that with the passage of time major changes have been taking place in the manufacturing sector of Pakistan which have made it more easy to substitute between energy and labour or between energy and capital. During the 1960s and the early 1970s factor prices were relatively stable and therefore major changes in production technology were not warranted. Energy, which constituted a small fraction of production cost, was used complementarily with other factor inputs. The need for substitution between the factor inputs would have been felt seriously only after major changes in the relative factor prices were experienced from the mid 1970s onwards. Since the production technology can be altered with some lapse of time, any flexibility in factor substitution can be attained only gradually.

A good example of such technological transformation is provided by the prolonged power shortage crisis during the 1980s, which led to power rationing through load-shedding devices. ${ }^{2}$ During this period some firms had learnt to make adjustments in the production process in order to continue their operations during load-shedding hours. Many firms also installed their own power generators to cope with power shortages. ${ }^{3}$

The new arrangements to increase power generation capacity with the help of private power producers, mostly foreign companies, have resulted in significant increases in tariffs. Further escalation in tariffs is almost certain because the purchase price of electricity from the independent power producers has been pegged to dollars and the value of rupee vis-à-vis dollar is suffering continuous erosion. The extraordinary increases in power tariffs during the recent past signify a shift in the policy stance. Unlike the previous policy of rationing, the physical scarcity of power is being translated into economic scarcity in terms of rising prices. In this respect the evidence of increase in substitution elasticities between energy and non-energy inputs is encouraging because it signifies that the manufacturing sector has gained the capability to adjust factor proportions under economic compulsions.

\section{CONCLUDING REMARKS}

The manufacturing sector of Pakistan has experienced a slight decline in total factor productivity during a period when technological change was expected to be a

\footnotetext{
${ }^{2}$ It may be noted that the average share of electricity in energy cost has been almost 60 percent during the period of analysis.

${ }^{3}$ Ahmad (1995) has shown that manufacturing firms had significantly recovered some of the losses from power shortage by installing their own power generators and resorting to process adjustment and over time work.
} 
source of productivity growth. The productivity loss can be attributed to various distortions rather than technological deterioration. These distortions include overemployment in the public-owned segment of the sector, misdirected capital market policies, lack of discipline in the capital market in the shape of subsidised loans, loan write-offs, and over-protection of certain industries, etc. Thus the first major contention of the study is that the removal of distortions has to be a fundamental intermediate objective of any meaningful policy package for the manufacturing sector of Pakistan.

It was further observed that the degree of substitution between labour and capital has been declining with the passage of time. Energy and labour have transformed from being complements of each other in the early years into being substitutes later on and the degree of substitutability has increased with the passage of time. The same results hold for the relationship between energy and capital. This is an important finding keeping in view the various energy crises Pakistan has seen in the form of oil price shocks and shortage of electricity. It appears that the manufacturing sector has gradually adjusted, at least partially, to the unfavourable odds. The increasing magnitude of substitution elasticity means that the prospects of changes in factor proportions are no more bleak. As electricity prices fully adjust to the new pricing policies in line with the expected rising cost of electricity from private power producers, the resulting price disincentive is likely to prompt the manufacturing sector to conserve electricity consumption.

The study also shows that the traditional labour-intensive techniques of production have been replaced gradually by modern techniques that use more energy per unit of output. This factor bias could have resulted from Pakistan's dependence on imported plants and equipment, which are designed to replace labour by energy due to the rising cost of labour in developed countries. However, in case of Pakistan the labour saving effects of the technological change have been partially offset by the tendency to over-employ labour in the public owned manufacturing units. Another reason for the bias towards energy using production techniques is the presence of distortions in the factor markets, such as non-payment of electricity and natural gas charges, resulting in reduced effective unit cost of energy. It is, therefore, essential to make the energy pricing policy more effective and to remove other distortions from the factor markets.

\section{REFERENCES}

Ahmad, E. (1995) Power Shortages and Economic Losses in Small and Medium Sized Manufacturing Firms of Gujranwala (Pakistan). The University of Newcastle, Callaghan, Australia. (Occasional Paper.)

Battese, G. E., and S. J. Malik (1987) Estimation of Elasticities of Substitution for CES Production Function using Data on Selected Manufacturing Industries in 
Pakistan. The Pakistan Development Review 26:2 161-77.

Battese, G. E. and S. J. Malik (1988) Estimation of Elasticities of Substitution for CES and VES Production Function using Firm-level Data for Food Processing Industries in Pakistan. The Pakistan Development Review 27:1 59-71.

Battese, G. E., S. J. Malik, and N. Sultana (1993) Capital Labour Substitution in the Large-scale Food Processing Industries in Pakistan: Some Recent Evidence. The Pakistan Development Review 32:4 847-57.

Burki, A. A., M. A. Khan, and B. Bratsberg (1997) Parametric Tests of Allocative Efficiency in the Manufacturing Sectors of India and Pakistan. Applied Economics 29:1 155-169.

Chishti, S., and F. Mahmud (1988) Energy Substitution in Pakistan’s Manufacturing Sector. Pakistan Economic and Social Review 26:1 17-64.

Chishti, S., and F. Mahmud (1991) The Energy Demand in the Industrial Sector of Pakistan. The Pakistan Development Review 30:1 83-88.

Christensen, L. R., and D. W. Jorgenson (1969) The Measurement of US Real Capital Input, 1929-1967. Review of Income and Wealth 293-320.

Christensen, L. R., and D. W. Jorgenson (1970) US Real Product and Real Factor Input, 1929-76. Review of Income and Wealth 19-50.

Idrees, M. (1998) Production Relations in the Manufacturing Sector of Pakistan. M.Phil. Thesis. Department of Economics, Quaid-i-Azam University, Islamabad.

Jones , H. (1975) An Introduction to Modern Theories of Economic Growth. Van Nostrand Reinhold (U.K.).

Guilkey, D. K., C. A. K. Lovel, and R. C. Sickless (1983) A Comparison of the Performance of Three Flexible Functional Forms. International Economic Review 24:3 591-616.

Kazi, S., Z. S. Khan, and S. A. Khan (1976) Production Relations in Pakistan's Manufacturing. The Pakistan Development Review 15:4 406-23.

Kazmi, N. (1981) Substitution Elasticities in Small and Household Manufacturing Industries in Pakistan. Pakistan Institute of Development Economics, Islamabad. (Research Report Series, No. 122.)

Khan, A. H. (1989) The Two-level CES Production Function for the Manufacturing Sector of Pakistan. The Pakistan Development Review 28:1 1-12.

Khan, A. E., and M. Rafiq (1993) Substitution among Labour, Capital, Imported Raw Materials, and Bank Credit in Pakistan's Manufacturing. The Pakistan Development Review 32:4 1259-1266.

Kemal, A. R. (1981) Substitution Elasticities in the Large-scale Manufacturing Industries of Pakistan. The Pakistan Development Review 20:1 1-36.

Mahmood, Z. (1989) Derived Demand for Factors in the Large-scale Manufacturing Sector of Pakistan. The Pakistan Development Review 28:4 731-742.

Mahmood, Z. (1992) Factor Price Shocks, Factor Substitution and their Implications 
for Policy. International Economic Journal 6:4.

Malik, S. J., M. Mustaq, and H. Nazli (1989) An Analysis of Production Relations in the Large Scale Textile Manufacturing Sector of Pakistan. The Pakistan Development Review 28:1 27-42.

McFadden, D. (1978) Estimation Techniques for the Elasticity of Substitution and other Production Parameters. In M. Fuss and D. McFadden (eds) Production Economics: A Dual Approach to Theory and Applications. Amsterdam: NorthHolland.

Zahid, S. N., M. Akbar, and S. A. Jaffry (1992) Technical Change, Efficiency, and Capital-labour Substitution in Pakistan's Large-scale Manufacturing Sector. The Pakistan Development Review 31:2 165-88. 


\section{Comments}

The study makes use of Generalised Leontief techniques to estimate cost functions for manufacturing industries in Pakistan for the period 1975-76 to 1990-91. It assesses the factor bias in technological change and nature of technological adjustment in response to changes in relative factor prices. This objective is achieved through estimating Allen's partial elasticity of substitution and Hick's elasticity of substitution between inputs such as capital, labour and energy.

The study is brief but it has a fairly ambitious agenda of research as it attempts to analyse the technological changes in the manufacturing sector from mid 70 s to end of 80s.

The underlying approach of the study is to adopt the neo-classical formulation by introducing disembodied and exogenous technical change. However, it is generally perceived that neo-classical formulations are not suitable for the analysis of economic conditions in the developing countries because of numerous built-in distortions in the factor and product markets. This could be one of the basic reasons for some of the contradictory results obtained in the study. The above conclusions can be substantiated from different results of the study as following:

(a) Unit cost of production has been increasing at the rate of 0.04 percent per annum on an average basis and therefore, no major factor productivity has taken place in the period 1975-76 to 1990-91.

(b) There has been a decline in productivity in the manufacturing sector due to technological deterioration.

(c) Manufacturing sector has experienced increasing costs due to shift towards inefficient manufacturing industries.

(d) The share of energy in total cost has been rising at the annual rate of 0.017 per point per year while the share of capital has been declining at the rate of 0.018 percent point.

The first three conclusions are apparently contradictory because on the one hand it has been claimed that unit costs of production have been rising at a nominal rate but then it is also suggested that there is a decline in productivity showing technological deterioration as well as allocative inefficiency. The allocative inefficiency have been explained in terms of distorted tariff structure which was meant to protect the otherwise inefficient industries. However, the study fails to realise that since 1975-76 there has been a continuous decline in nominal tariff rates bringing about a reduction in the market and factor distortions. For that reason, efficiency of the manufacturing sector should have increased rather than have declined.

The study establishes a rising share of energy in the total cost of the manufacturing sector and a declining share of capital cost with the labour share being almost constant. The conclusion of the study therefore, that there has been greater 
intensity of energy use over time, is not corroborated by the subsequent discussion of the study.

The study points out that higher energy prices in 70 s necessitated a substitution of energy with other inputs such as labour and capital and that the manufacturing sector has gained capabilities to adjust to factor proportions under economic compulsions. If this conclusion is accepted then there could be no room to suggest that technological change has been towards greater use of energy itemwise techniques of production.

The study raises the basic question whether Pakistan's manufacturing sector has the capability to readily make adjustments to substitute labour for electricity or oil in response to higher prices of energy inputs as experienced at different points of time in 70s and 80s. Whereas this question has not been answered in the study, it reaches a "contrary" conclusion that the traditional labour-intensive techniques of production have been replaced gradually by modern techniques that use more energy per unit of output and then an attempt is made to substantiate this conclusion by emphasising that this factor bias could have resulted from Pakistan's dependence on imported plants and equipment which are designed to replace labour by energy due to the rising cost of labour in the developed countries. This is obviously a naive way of looking at the otherwise extremely complex phenomenon of change in the industrial structure of any country over time.

The basic point is that if Pakistan's manufacturing sector has had built-in capacity to adjust rapidly to changes in factor prices then the manufacturing sector should have adopted more labour-intensive and capital-intensive technologies rather than energy intensive techniques of production. However, the study establishes that the process of technological change has been inverse and there has been greater use of energy - itemwise technology rather than labour and capital intensive techniques of output in the manufacturing of Pakistan.

Looking at the study from a holistic point of view, there is a need to focus at the micro-level structure of manufacturing industries of Pakistan such as textiles, leather, engineering, fertiliser, sugar and cement industries to identify the changes in these industries and the degree of factor substitution resulting from variability in the input costs. Therefore, the main contention of the study that the removal of distortions has to be a fundamental objective of any meaningful policy package for the manufacturing sector of Pakistan is too generalised to be of any practical use. The study has to be industry specific with precise definition of tariff structure for each industry which could help in removing the distortions and in helping a revival of Pakistan’s ailing manufacturing sector.

Central Board of Revenues,

Aqdas Ali Kazmi Islamabad. 